\title{
HUBUNGAN PRE-MENOPAUSE DENGAN KEJADIAN HIERTENSI PADA WANITA DI RT 11 RW 05 KELURAHAN BANJARBENDO SIDOARJO
}

\author{
Farida Umamah, Aprillia Lestari \\ Fakultas Keperawatan dan Kebidanan \\ Universitas Nahdlatul Ulama Surabaya - J1 Smea 57 Surabaya \\ Email : umamahfarida@unusa.ac.id
}

\begin{abstract}
Abstrak :The relationship between pre-menopause women with incidence of hypertension in RT 11 RW 05 Banjarbendo village Sidoarjo. Menopause women have increasing blood pressure is higher than pre-menopause women, it caused by decreasing of hormonal levels. Initial data showed in February 2015 in RT 11 RW 05 Banjarbendo village was obtained 6 out of 10 women or $60 \%$ women had symptoms of hypertension in premenopause women. The purpose of this study is to analyze the relationship between premenopause women with incidence of hypertension in RT 11 RW 05 Banjarbendo village Sidoarjo.It use analytic design, with cross sectional approach. The population were 61 women. The sample were 52 respondents taken by simple random sampling technique. The independent variable was the incidence of hypertension and the dependent variable was the incidence of pre-menopause. Data were collected by using check list. Analyzed by chi square test $(\alpha=0.05)$. Study results showed almost all pre-menopause women and most women them had hypertension. Results test $\rho=0.001<\alpha=0.05$. so H0 is rejected and H1 is accepted. The conclusion of this study is there is relationship between Pre-menopause with incidence of hypertension In women In RT 11 RW 05 Banjarbendo village Sidoarjo. Suggested for women to understand and have knowledge about the signs of pre-menopause and the incidence of hypertension and Health staff to provide information to the women about the signs of pre-menopause and hypertension .
\end{abstract}

Abstrak : Wanita mengalami peningkatan tekanan darah setelah menopause lebih tinggi dibandingkan dengan wanita yang mengalami sebelum menopause yang disebabkan oleh penurunan kadar hormonal. Data awal yang menunjukkan pada bulan Februari tahun 2015 di RT 11 RW 05 Kelurahan Banjarbendo didapatkan sebesar 6 dari 10 wanita atau 60 dari 100\% wanita mengalami gejala hipertensi pada wanita premenopause. Tujuan menganalisis hubungan pre-menopause dengan kejadian hipertensi di RT 11 RW 05 Kelurahan Banjarbendo Sidoarjo. Desain yang digunakan adalah analitik, dengan pendekatan cross sectional. Populasi adalah wanita yang berusia 40-55 tahun yang tidak menderita hipertensi 61 orang dan sampel sebesar 52 responden. Diambil dengan menggunakan teknik simple random sampling. Variabel independen adalah kejadian hipertensi dan variabel dependen adalah kejadian pre-menopause, pengumpulan data dengan kuisioner. Analisis uji chi square $(\alpha=0,05)$. Hasil didapatkan hampir seluruhnya wanita yang mengalami pre-menopause, dan sebagian besar wanita mengalami kejadian hipertensi. Hasil uji $\rho=0,001<\alpha=0,05$. Maka $\mathrm{H}_{0}$ ditolak dan $\mathrm{H}_{1}$ diterima. Kesimpulan dari penelitian ini adalah ada hubunganantaraPremenopause Dengan Kejadian Hipertensi Pada Wanita Di RT 11 RW 05 Kelurahan Banjarbendo Sidoarjo. Diharapkan wanita mampu memahami dan mengetahui tentang tandatanda pre-menopause dan kejadian hipertensi dan memberikan pemahaman kepada para wanita mengenai tanda-tanda pre-menopause dan hipertensi.

Kata kunci : Pre-menopause, Hipertensi, Kejadian 


\section{PENDAHULUAN}

Seseorang yang mengalami hipertensi atau yang lebih dikenal dengan penyakit tekanan darah tinggi adalah suatu keadaan dimana seseorang mengalami peningkatan tekanan darah di atas normal yang mengakibatkan peningkatan angka kesakitan (mordibitas) dan angka kematian (mortalitas). Masyarakat dan kondisi alam yang kompleks mengakibatkan banyak masalah yang bermuncukan terutama hipertensi. Wanita mengalami peningkatan tekanan darah setelah menopause, lebih tinggi dibandingkan dengan wanita yang mengalami sebelum menopause yang disebabkan oleh penurunan kadar hormonal (Wulandari, 2011). Wanita pre-menopause mengalami hipertensi (tekanan darah tinggi) di daerah RT 11 RW 05 Kelurahan Banjarbendo Sidoarjo.

Penderita hipertensi cenderung mengalami peningkatan, salah satunya di puskesmas Tambakan. Berdasarkan data yang diperoleh dari Puskesmas, menunjukkan jumlah kasus hipertensi meningkat dari tahun 2011 hingga tahun 2012. Seseorang yang mengalami hipertensi pada tahun 2012 sebesar 1.260 (DepartemenKesehantan, 2012). Penderita hipertensi di perkotaan memiliki presentasi lebih besar dibandingkan dengan jumlah penderita di pedesaan. Wanita yang mengalami pre-menopause pada tahun 2010 sebesar 37.476.757 jiwa di Jawa Timur

Penelitian Rina tentang hubungan dukungan keluaraga dengan tingkatan hipertensi pada anggota keluarga yang menderita hipertensi di wilayah kerja puskesmas Wonokromo Surabaya tahun 2013 didapatkan sebesar $76 \%$ anggota keluarga mengalami hipertensi. Perempuan mengalami pre-menopause meningkat pada tahun 2008 jumlah ibu pre-menopause $1.216 .908 \quad(34,94 \%)$, tahun $20091.877 .153(31,79 \%)$, tahun $2010 \quad 1.936 .209 \quad(36,63 \%) \quad$ (Danas Kesehatan Jawa Timur, 2008). Data awal yang penulis lakukan pada bulan Februari tahun 2015 di RT 11 RW 05 Kelurahan Banjarbendo didapatkan sebesar 6 dari 10 wanita atau 60 dari $100 \%$ wanita mengalami gejala hipertensi pada wanita premenopause. Seseorang wanita pre-menopause mengeluhkan keluarnya keringat dingin pada malam hari, badan terasa panas, tengkuk terasa kaku, dan mengeluhkan pusing.

Wanita yang mengalami hipertensi dipengaruhi oleh beberapa faktor yaitu faktor keturunan, faktor lingkungan, usia, stres, gaya hidup, garam, merokok, kurang olahraga atau aktivitas, dan pola makan. Wanita usia lanjut yang mengalami hipertensi disebabkan oleh sindrome pre-menopause. Bagi kebanyakan perempuan, gejala premenopause akan muncul pada rentang waktu usia 40 tahun (Proverawati, 2010). Wanita yang mengalami masa premenopause akan mengalami gejala puncak (klimakterik) dan mempunyai masa transisi atau masa peralihan. Fase ini disebut dengan periode klimakterium (climacter $=$ tahun perubahan, pergantian tahun yang berbahaya). Periode klimakterium ini disebut pula sebagai periode kritis yang ditandai dengan rasa terbakar (hot flush), adanya gejolak panas yang terjadi suatu peningkatan tekanan darah baik sistol maupun diastol. Rasa panas terjadi akibat peningkatan aliran darah di dalam pembuluh darah wajah, leher, dan punggung. Etiologi rasa panas masih belum diketahui dengan pasti, namun mungkin disebabkan oleh labilnya pusat termoregulator tubuh di hipotalamus yang diinduksi oleh penurunan kadar esterogen dan progesteron (Proverawati, 2010). Peningkatan tekanan darah pada usia klimakterium terjadi secara bertahap, kemudian menetap dan lebih dari tekanan darah sebelumnya. 
Gangguan vasomotor yang dapat menyebabkan hipertensi pada wanita pre-menopause dapat ditanggulangi dengan cara menganjurkan untuk menghindari makanan atau minuman yang pedas, berkafein, beralkohol, dan bergula. Cara meminimalkan gangguan ini yaitu hindari rasa panik, olah raga yang teratur, banyak minum air putih, berpakaian yang longgar dan kalau perlu mengkonsumsi vitamin untuk mengurangi pancaran panas. Termugulator tubuh di hipotalamus menjadi labil dan diharapkan tidak terjadi keluar keringat yang berlebihan pada malam hari. Selain itu bisa melakukan terapi hormon esterogen dan progesteron dalam menghilangkan gejala vasomotor.

\section{METODE PENELITIAN}

Penelitian dilakukan secara observasional analitik dengan pendekatan cross sectional. Unit analisis penelitian wanita yang berumur 40-55 tahun yang memiliki tekanan darah meningkat, populasi wanita sebanyak 61 orang dengan cara simple random sampling. Variabel bebas (independent) yaitu kejadian hipertensi. Variabel terkait (dependent) yaitu kejadian premenopause. Pengumpulan data dilakukan melalui kuesioner dan observasi secara terstruktur. Uji dilakukan dengan menggunakan uji $C h i$ Square dengan nilai kemaknaan $\alpha=(0,05)$ berarti $\rho<\alpha$ sehingga $\mathrm{H}_{0}$ ditolak jika nilai signifikannya $\rho<$ value $(<0,05)$ berarti ada hubungan.

\section{HASIL PENELITIAN}

\section{Data Umum}

\section{Karakteristik \\ Berdasarkan Usia}

Responden

Pengumpulan data umum meliputi usia dengan tanda-tanda wanita pre- menopause dan wanita yang tidak hipertensi.

Tabel 1. Distribusi frekuensi responden berdasarkan usia di RT $11 \mathrm{RW}$ 05 Kelurahan Banjarbendo Sidoarjo

\begin{tabular}{lcc}
\hline Ssia (Tahun) & Frekuensi & $\begin{array}{c}\text { Persentase } \\
(\%)\end{array}$ \\
\hline $\begin{array}{c}\text { s45 } \\
>45\end{array}$ & 14 & 26,9 \\
& 38 & 73,1 \\
\hline Jumlah & 52 & 100 \\
\hline $\begin{array}{l}\text { Tabel 5.1 } \\
\text { responden } \\
\text { tahun. }\end{array}$ & & \\
\hline
\end{tabular}

\section{Karakteristik responden berdasarkan paritas}

Tabel 2 Distribusi frekuensi responden berdasarkan jumlah anak di RT 11 RW 05 Kelurahan Banjarbendo Sidoarjo.

\begin{tabular}{lcc}
\hline \multicolumn{1}{c}{ Anak } & Frekuensi & $\begin{array}{c}\text { Persentase } \\
(\%)\end{array}$ \\
\hline $\begin{array}{l}\text { Primipara } \\
\text { (1anak) }\end{array}$ & 0 & 0 \\
$\begin{array}{l}\text { Multipara } \\
(2-4 \text { anak) }\end{array}$ & 40 & 76,9 \\
$\begin{array}{l}\text { Grandemulti } \\
\text { (> anak) }\end{array}$ & 12 & 23,1 \\
\hline \multicolumn{1}{c}{ Jumlah } & 52 & 100 \\
\hline
\end{tabular}

Tabel 2 menunjukkan bahwa dari 52 responden hampir seluruhnya multipara.

Karakteristik responden berdasarkan usia kehamilan yang pertama

Tabel 3 Distribusi frekuensi responden berdasarkan usia kehamilan yang pertama di RT 11 RW 05 Kelurahan Banjarbendo Sidoarjo.

$\begin{array}{ccc}\text { Usia } & \text { Frekuensi } & \begin{array}{c}\text { Persentase } \\ (\text { Tahun })\end{array} \\ \end{array}$




\begin{tabular}{lll}
\hline$<21$ & 41 & 78,8 \\
$21-35$ & 11 & 21,2 \\
& & \\
\hline Jumlah & 52 & 100 \\
\hline
\end{tabular}

Tabel 3 menunjukkan bahwa dari 52 responden hampir seluruhnya $(78,8 \%)$ kehamilan pertama pada usia $<21$ tahun.

\section{Karakteristik responden berdasarkan diet}

Tabel 4 Distribusi frekuensi responden berdasarkan yang menjalani diet di RT 11 RW 05 Kelurahan Banjarbendo Sidoarjo.

\begin{tabular}{ccc}
\hline Diet & Frekuensi & $\begin{array}{c}\text { Persentase } \\
(\%)\end{array}$ \\
\hline Tidak & 42 & 80,8 \\
Ya & 10 & 19,2 \\
\hline Jumlah & 52 & 100 \\
\hline
\end{tabular}

Tabel 4 menunjukkan bahwa dari 52 responden hampir seluruhnya $(80,8 \%)$ tidak menjalani program diet.

\section{Data Khusus}

\section{Karakteristik responden berdasarkan} pre-menopause

Tabel 5 Distribusi frekuensi responden berdasarkan pre-menopause di RT 11 RW 05 kelurahan Banjarbendo Sidoarjo.

\begin{tabular}{lcc}
\hline $\begin{array}{l}\text { Pre- } \\
\text { menopause }\end{array}$ & $\begin{array}{c}\text { Frekuens } \\
\mathrm{i}\end{array}$ & $\begin{array}{c}\text { Persentase } \\
(\%)\end{array}$ \\
\hline $\begin{array}{l}\text { Belum Pre- } \\
\text { menopause }\end{array}$ & 12 & 23,1 \\
$\begin{array}{l}\text { Premenopaus } \\
\text { e }\end{array}$ & 40 & 76,9 \\
\hline \multicolumn{1}{c}{ Jumlah } & 52 & 100 \\
\hline
\end{tabular}

Tabel 5 menunjukkan bahwa dari 52 responden hampir seluruhnya $(76,9 \%)$ mengalami pre-menopause.

\section{Karakteristik responden berdasarkan kejadian tekanan darah meningkat}

Tabel 6 Distribusi frekuensi responden berdasarkan kejadian hipertensi di RT 11 RW 05 Kelurahan Banjarbendo Sidoarjo.

\begin{tabular}{lcc}
\hline $\begin{array}{l}\text { Kejadian } \\
\text { hipertensi }\end{array}$ & Frekuensi & Persentase(\%) \\
\hline $\begin{array}{l}\text { Tekanan } \\
\text { Darah }\end{array}$ & 22 & 42,3 \\
Normal & & \\
Tekanan & 30 & 57,7 \\
$\begin{array}{l}\text { Darah } \\
\text { Meningkat }\end{array}$ & &
\end{tabular}

\begin{tabular}{lll}
\hline Jumlah & 52 & 100 \\
\hline
\end{tabular}

Tabel 6 menunjukkan bahwa dari 52 responden sebagian besar $(57,7 \%)$ mengalami tekanan darah meningkat.

\section{Tabulasi silang hubungan pre- menopause dengan hipertensi}

Tabel 7 Tabulasi silang hubungan premenopause dengan kejadian hipertensi pada wanita di RT 11 RW 05 Kelurahan Banjarbendo Sidoarjo

\begin{tabular}{|c|c|c|c|c|}
\hline \multirow{4}{*}{$\begin{array}{c}\text { Pre- } \\
\text { Menopause }\end{array}$} & \multicolumn{4}{|c|}{ Kejadian Hipertensi } \\
\hline & \multirow{2}{*}{\multicolumn{2}{|c|}{$\begin{array}{c}\text { Tidak } \\
\text { Hipertensi }\end{array}$}} & \multirow{2}{*}{\multicolumn{2}{|c|}{$\begin{array}{c}\text { Hipertensi } \\
\text { Total }\end{array}$}} \\
\hline & & & & \\
\hline & $\mathrm{n}$ & $(\%)$ & $\begin{array}{c}\mathrm{n} \\
(\%)\end{array}$ & $\begin{array}{c}\mathrm{n} \\
(\%)\end{array}$ \\
\hline \multirow{3}{*}{ Tidak } & 10 & 83,3 & 2 & 12 \\
\hline & & & 16,7 & 100 \\
\hline & 12 & 30,0 & 28 & 40 \\
\hline $\mathrm{Ya}$ & & & 70,0 & 100 \\
\hline \multirow[t]{2}{*}{ Jumlah } & 22 & 42,3 & 30 & 52 \\
\hline & & & 57,7 & 100 \\
\hline
\end{tabular}

Tabel 7 diketahui dari 52 responden didapatkan 12 responden belum 
mengalami pre-menopause dengan kejadian tidak hipertensi hampir seluruh $(83,3 \%)$. Sedangkan 40 responden yang mengalami pre-menopause sebagian besar $(70,0 \%)$ mengalami kejadian hipertensi.

\section{PEMBAHASAN}

Berdasarkan uji korelasi Chi Square dengan tingkat kemaknaan $\alpha=0,05$, didapatkan nilai $\rho=0,001$ yang berarti $\rho$ $<\alpha$, maka $\mathrm{H}_{0}$ ditolak berarti ada hubungan antara Pre-menopause Dengan Kejadian Hipertensi Pada Wanita Di RT 11 RW 05 Kelurahan Banjarbendo Sidoarjo. Hasil tabulasi silang didapatkan dari 40 responden dengan pre-menopause sebagian besar $(70,0 \%)$ mengalami kejadian hipertensi, sedangkan 12 responden yang belum mengalami pre-menopause sebagian kecil $(16,7 \%)$ tidak mengalami hipertensi.

Berdasarkan data diatas dapat disimpulkan bahwa seseorang yang mengalami pre-menopause terdapat tanda-tanda tekanan darah tinggi, hasil penelitian didukung pendapat Proverawati (2010) yang menyatakan bahwa pre-menopause dapat mempengaruhi tekanan darah seseorang menjadi meningkat. Pengaturan makanan seperti makanan pedas, kopi dan minuman beralkohol sebaiknya dihindari karena dapat menyebabkan efek yang mengganggu kesehatan dan meningkatkan gejala sindrom premenoupause. Alkohol bisa merubah kolestrol baik apabila tidak mengkonsumsi berlebihan, sedangkan merokok sudah terbukti menurunkan kolestrol baik serta dapat menurunkan kadar hormon estrogen pada wanita sehingga mempercepat terjadinya premenoupause. Mengkonsumsi kopi secara berlebihan menyebabkan gangguan kesehatan seperti jantung berdebar, gelisah, insomnia, gugup, tremor dan mual muntah. Penderita hipertensi yang mengkonsumsi kopi berlebihan dapat meningkatkan tekanan darah lebih tajam karena senyawa kafein bisa menyebabkan tekanan darah meningkat dan jika wanita mengkonsumsi terlalu banyak kopi bisa mengurangi kesuburan. Pada wanita gaya hidup sehat dengan rutin berolah raga dapat memperkecil terjadinya stres, mengurangi tekanan darah, menghilangkan gangguan sakit kepala, sakit punggung.

Salah satu cara yang mudah untuk mengurangi tanda-tanda tersebut adalah dengan teknik relaksasi yang bisa dilakukan seseorang dirumah maupun mandiri. Relaksasi dapat memberikan keuntungan, antara lain : a). Memberikan rasa tenang, b). Mengurangi tekanan darah, c). Mengatur pernapasan, dan d). Mengurangi atau bahkan terhindar dari serangan panik akibat kekurangan oksigen.

\section{SIMPULAN}

Simpulan yang didapatkan dari hasil penelitian dan pembahasan mengenai Hubungan Pre-menopause Dengan Kejadian Hipertensi Pada Wanita di RT 11 RW 05 Kelurahan Banjarbendo Sidoarjo, sebagai berikut :

1. Wanita di RT 11 RW 05 Kelurahan Banjarbendo Sidoarjo hampir seluruhnya mengalami premenopause.

2. Wanita di RT 11 RW 05 Kelurahan Banjarbendo Sidoarjo sebagian besar mengalami kejadian hipertensi.

3. Ada hubungan pre-menopause dengan kejadian hipertensi di RT 11 RW 05 Kelurahan Banjarbendo Sidoarjo.

\section{SARAN}

1. Bagi Petugas Kesehatan

Memberikan pemahaman kepada para wanita mengenai tanda-tanda pre-menopause dan hipertensi. 
2. Bagi Wanita

Diharapkan mampu memahami dan mengetahui tentang tanda-tanda premenopause dan kejadian hipertensi.

\section{DAFTAR PUSTAKA}

Bramantyo, Lastiko. (2005). Kiat Sehat dan Bahagia Di Usia Menopause. Jakarta, Puspa Swara.

Clark, Jan. (2008). Fit dan Bugar Saat Menopause. Jakarta : Erlangga.

Campbell Neil, A. (2010). Biologi, Edisi Kedelapan Jilid 3. Jakarta, Erlangga.

Dalimartha, Setiawan., dkk. (2008). Care Your Self Hipertensi. Jakarta, Plus.

Gunawan lany. (2006). Hipertensi Tekanan Darah Tinggi. Yogyakarta, Kanisius (Anggota IKAPI).

Hardjana. (2009). Perubahan Fisik Menopause. Jakarta : Erlangga.

Hart, Julian Tudor., Fahey, Tom., Savage, Wendy. (2009). Tanya Jawab Seputar Tekanan Darah Tinggi Edisi 2. Jakarta, Arcan.

Jain, Ritu. (2011). Pengobatan Alternatif Untuk Mengatasi Tekanan Darah. Jakarta, PT Gramedia Pustaka Umum.

Kusmiran, Eni. (2011). Kesehatan Reproduksi Remaja dan Wanita. Jakarta : Salemba Medika.

Notoatmodjo, Soekidjo. (2010). Metodologi Penelitian Kesehatan. Jakarta, Rineka Cipta

Nursalam. (2011). Konsep dan Penerapan Metodologi Penelitian Ilmu Keperawatan: Pedoman Skripsi, Tesis, dan Instrument Penelitian Keperawatan Edisi 2. Jakarta, Salemba Medika

Manuaba, Chandranita., dkk. (2009). Memahami

Kesehatan
Reproduksi Wanita. Jakarta, EGC.

Martha, Karnia. (2012). Panduan Cerdas Mengatasi Hipertensi. Yogyakarta. Araska.

Millah, Ainul. (2010). Darah Kebiasaan Wanita. Solo, Aqwam.

Proverawati Atikah, MPH. (2010). Menopause dan Sindrome Premenopause. Yogyakarta, Nuha Medika.

Rebecca dan Brown, pam. (2007). Menopause. Jakarta, Erlangga.

Sanif, Edial. (2009). Hipertensi Pada Wanita.

www.jantunghipertensi.com. Diakses pada tanggal 28 Januari 2015, 09.18 WIB.

Sufyan, Asep R. (2011). Biologi Reproduksi. Bandung, Refika Aditama.

Susilo, Yeksi. (2011). Cara Jitu Asam Urat dan Hipertensi. Jakarta, Penebar Plus.

Widanti Tri, Okrina. (2010). Hipertensi Dan Menopause. www.deherba.com. Diakses tanggal 25 Januari 2015, 20.10 WIB.

Wulandari, Ari., dkk. (2011). Cara Jitu Mengatasi Hipertensi. Yogyakarta, Andi. 